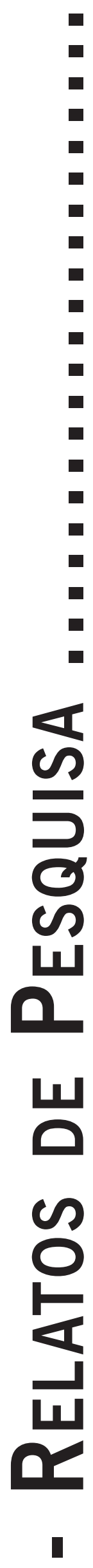




\title{
A TEMPORALIDADE DO AQUI-E-AGORA GESTÁLTICO: IMPLICAÇÕES TEÓRICAS E PRÁTICAS
}

\author{
The temporality of the Gestaltic here-and-now: Theoretical and practical implications
}

La temporalidad del aquí-y-ahora gestáltico: implicaciones teóricas y prácticas

\author{
Paula Arenhart \\ JOANNELIESE DE LUCAS FREITAS
}

\begin{abstract}
Resumo: O aqui-e-agora é um conceito relevante e característico da Gestalt-terapia. Entretanto o termo encontra diferentes acepções na literatura, revelando um problema conceitual com repercussões sobre a prática clínica. O presente trabalho preocupou-se em investigar a forma pela qual o aqui-e-agora é descrito e compreendido por profissionais da área. Foram realizadas três entrevistas com teóricos da Gestalt-terapia, analisadas pelo método fenomenológico-qualitativo. As entrevistas evidenciaram quatro eixos principais de significados: O mal-entendido conceitual, A especialização do aqui-e-agora como contraposição a outras perspectivas temporais, Definição do termo e O lugar que o aqui-e-agora ocupa na prática clínica. Os resultados obtidos apontam para o fato de que o termo é frequentemente utilizado de modo equivocado. Evidenciam um aqui-e-agora que difere de uma simples presentificação, abrangendo um momento psicoterapêutico em que o sujeito está fluindo no campo temporal existencial. Isso significa que, mesmo na prática, o termo excede configurações técnicas, instrumentais ou metodológicas. Há, portanto, a necessidade de se compreender o aqui-e-agora fora de conotações valorativas entre passado, presente e futuro, retornando ao suporte filosófico da fenomenologia. Palavras-chave: Aqui-e-agora; Fenomenologia; Gestalt-terapia; Temporalidade.
\end{abstract}

Abstract: The here-and-now is a relevant and distinctive concept of Gestalt therapy. However, the word has different meanings in literature, which reveal a conceptual problem with consequences for clinical practice. This work aims to investigate how practioners in Gestalt therapy describe here-and-now. In other that, we interviewed three thinkers in Gestalt therapy and submitted the corpus to a phenomenological qualitative analysis. The interviews highlighted four main groups of meanings: Conceptual misunderstanding, Focus on here-and-now as a counterpoint to other temporal perspectives, Definition of the term and Place here and now assumes in the clinical practice. The results show that here and now differs from a pure present moment, covering a psychotherapeutic moment in which the subject is flowing in the existential temporal field. It means that even in practice the term exceeds technical, instrumental or methodological settings. Therefore, there is the requirement to reconnect it to philosophical phenomenology in order to understand here and now above past, present and future's evaluative connotations. Keywords: Here-and-now; Phenomenology; Gestalt-therapy; Temporality.

Resumen: El aquí-y-ahora es un concepto relevante y distintivo de la terapia Gestáltica. Sin embargo el término presenta diferentes significados en la literatura, que revelan un problema conceptual con implicaciones para la práctica clínica. Este estudio ha investigado la forma en que el aquí-y-ahora es descrito y comprendido por los profesionales. Se realizaron tres entrevistas con teóricos de la terapia Gestáltica, analizadas segundo el método fenomenológico cualitativo. Las entrevistas destacaron cuatro grupos principales de significados: El malentendido conceptual, la especialización del aquí-y-ahora frente a otros marcos de tiempo, Definición de la expresión y el lugar que el aquí-y-ahora ocupa en la práctica clínica. Los resultados apuntan al hecho de que lo término es a menudo utilizado erróneamente, revelan un aquí-y-ahora que se diferencia de un momento presente puro porque se refiere a un momento psicoterapéutico en lo cual el sujeto está fluyendo en el campo temporal existencial. Esto significa que incluso en la práctica, el término excede las configuraciones técnicas, instrumentales o metodológicas. Por tanto, hay la necesidad de comprender el aquí-y-ahora más allá de las connotaciones valorativas de pasado, presente y futuro, para que se regrese a la base filosófica de la fenomenología.

Palabras-clave: Aquí-y-ahora; Fenomenología; Gestalt-terapia; Temporalidad.

O presente trabalho nasce de uma observação cotidiana sobre divergências na compreensão do termo gestáltico “aqui-e-agora”. Carmo (2004) destaca o aqui-e-agora como um conceito que seria, segundo ela, um dos que mais caracterizaria a abordagem e, ao mesmo tempo, um dos menos compreendidos nos meios acadêmicos, pois é entendido desde uma perspectiva em que "presente, passado e futuro são percebidos desconectados" (p. 29).
Deste modo, percebe-se que problemas de compreensão e aprofundamento, daquilo que Saddi (2004) denomina pressupostos teórico-filosóficos básicos da teoria gestáltica, envolvem diretamente confusões e incoerências no próprio exercício clínico do Gestalt-terapeuta. É, portanto, necessário considerar a relevância da discussão sobre o termo a partir da aparente e equivocada simplicidade do seu significado. 
Em Ego, fome e agressão, F. Perls (1942/2002) esboça as primeiras considerações acerca da temporalidade para a Gestalt-terapia. Dentre as críticas esboçadas na obra, encontram-se aquelas que se dirigiam às abordagens psicológicas que estruturavam suas práticas na necessidade de um retorno às experiências passadas. Para o autor, tais abordagens afastavam a pessoa de sua própria experiência, impelindo-a a buscar no passado uma interpretação para a "causa” de seu sintoma. Segundo D’Acri, Lima \& Orgler (2012) apesar de nesse primeiro esboço Perls já ter se oposto a uma lógica temporal causal que direciona a pessoa para fora da sua vivência presente, é somente em Gestalt-terapia (Perls, Hefferline \& Goodman, 1997) que o termo aqui-e-agora é formalmente estruturado e formatado a partir de uma leitura fenomenológica da temporalidade. Ainda que nessa obra seja pouco frequente a utilização direta do termo aqui-e-agora, é nela que os autores propõem a re-atualização das situações inacabadas, ou seja, aquelas situações que apesar de terem origem anterior ainda persistem no momento presente. As lembranças e projetos futuros deveriam, então, ser compreendidos como vivências atuais, nas circunstâncias atuais. A vinculação com a realidade concreta faz com que não exista dependência de outra coisa que não o momento presente, tal qual o passado remoto, por exemplo, oferecendo assim, uma abertura da possibilidade de espontaneidade criativa em que o assimilar da novidade não é "um mero agregamento de situações inacabadas do organismo, mas uma configuração que contém material novo do ambiente" (Perls et al., 1997, p. 48).

Não há consenso entre os autores e tradutores de Gestalt-terapia quanto à ortografia do termo. Em duas das principais obras traduzidas para o português: Gestalt-terapia (Perls et al., 1997) e A abordagem Gestáltica e a Testemunha Ocular da Terapia (Perls, 2012), assim como no Dicionário de Gestalt-Terapia (D’Acri et al., 2012) o termo é redigido como "aqui e agora”. Entretanto, entende-se que as noções espaço-temporais (aqui-agora) não podem ser compreendidas isoladamente. Além disso, é necessário considerar o aqui-e-agora como uma especialização e diferenciação da própria abordagem gestáltica que o implica enquanto elemento filosófico fundamental orientado por uma perspectiva fenomenológica. Por essas razões no presente trabalho optamos por utilizar a ortografia do "aqui-e-agora" que está de acordo com a maioria das referências utilizadas, inclusive em outra importante obra, a saber, Gestalt-Terapia Integrada (Polster \& Polster, 2001).

D'Acri et al. (2012) definem o significado do termo aqui-e-agora a partir de duas principais noções. A primeira remete ao modo pelo qual o termo manifesta a propriedade temporal do sistema self, que será mais detalhadamente explorado posteriormente, enquanto a segunda refere-se ao destino dessa perspectiva na intervenção clínica. Considerando que o termo surge no contexto do fazer psicoterapêutico e, portanto, se aplica à prática clínica, entende-se que a re-experienciação atual daquilo que é de interesse da pessoa, origina a possibilidade de abertura dos horizontes passado e futuro, por meio de dados reatualizados no aqui-e-agora (D'Acri et al., 2012). Nesse sentido, o termo, em sua compreensão ampliada, encerra uma perspectiva psicoterapêutica em que o processo de awareness sempre acontece no aqui-e-agora por meio da apropriação da existência presente, o que possibilita o reestabelecimento da dinâmica espaço-temporal e a reconfiguração da sua trajetória de vida (Carmo, 2004). Para Polster e Polster (2001) o passado e o futuro formam os limites da experiência presente, facilitando o reconhecimento do que já foi e do que pode vir a ser. A pessoa deixaria, então, de ser percebida como um conjunto de partes dissociadas da personalidade e passa a ser compreendida em sua inteireza, na integração consigo mesma e com as relações dinâmicas que articula temporalmente (Mesquita 2011).

Perls et al. (1997) afirmam que é só no aqui-e-agora que se pode ter consciência das próprias capacidades sensoriais, motoras e intelectuais. E dessa forma, propõem uma terapia que consiste na análise da estrutura interna da experiência concreta, promovendo mais a concentração no padrão de interrupções da pessoa do que no conteúdo próprio da interrupção. Isso significa que o foco na Gestalt-terapia é redirecionado para como a experiência está sendo vivida, relembrada e retida no presente. O aqui-e-agora abrange uma conscientização que vai além das categorias de conteúdo (porque), das abstrações, verbalizações ou relações causais traçadas, para incluir as formas, a relação e a corporeidade que surgem no aqui-e-agora por meio das realidades sensoriais e motoras disponíveis (Costa, 2004; Mesquita, 2011; Perls, 2012; Perls et al., 1997; Polster \& Polster, 2001). Perls et al. (1997) destacam a importância da expressão facial, do tom de voz, da sintaxe, da postura, do afeto, da omissão e da consideração ou falta de consideração. Costa (2004) salienta que os gestos, assim como os pensamentos, revelam o si-mesmo que se interrompeu. Polster e Polster (2001) descrevem as expressões simbolizadas na eloquência verbal, no choro, no grito, no soco e na repreensão. A flexibilização daquilo que havia enrijecido no passado é passível de ser revivido então, por meio dos recursos corporais que a pessoa dispõe no momento.

Ainda que seja um tema de extrema relevância para a prática gestáltica, há pouca referência atual no que concerne às reflexões teóricas sobre o tema, principalmente às implicações clínicas referentes aos diversos entendimentos sobre o aqui-e-agora. Constatando-se uma necessidade de maior compreensão desse fenômeno no campo da Gestalt-terapia e suas implicações na prática psicológica, a presente pesquisa teve como objetivo investigar a forma como o aqui-e-agora é descrito e compreendidos por profissionais reconhecidos da abordagem. 


\section{Método}

Trata-se de um estudo exploratório, de caráter qualitativo. Os dados qualitativos fornecidos por cada relato foram submetidos a uma análise fenomenológica hermenêutica de Van Manen (1990). O foco do desenho metodológico - desde a construção da entrevista até a análise - foi investigar a percepção dos psicólogos sobre a temática do aqui-e-agora e sobre as suas vivências e de seus pacientes em sua prática clínica. A percepção contribui para a compreensão das estruturas das experiências vividas como apreensão Temática (Van Manen, 1990). Segundo Van Manen, temas fenomenológicos são estruturas que apontam para o sentido que somos capazes de produzir sobre alguma experiência, é modo de abertura do mundo. É importante notar que os temas são estruturas que dão forma aos sentidos, descrevendo os conteúdos das vivências relatadas pelos participantes.

\section{Participantes}

Foram realizadas entrevistas com três profissionais da psicologia e representantes da Gestalt-terapia, de ambos os sexos, atuantes há mais de 30 anos na área e residindo atualmente nas regiões de Curitiba-PR e São Paulo-SP. Desses, apenas um dos profissionais não está atualmente exercendo a prática clínica, entretanto, os três estão inseridos no contexto acadêmico e participando ativamente dos debates teóricos.

\section{Procedimentos}

Para realização de todas as entrevistas foram apresentados os Termos de Consentimento Livre e Esclarecido (TCLE) que informava ao participante os detalhes referentes à pesquisa, seu caráter voluntário e confidencial, bem como todos seus direitos. Foi elaborado um roteiro de entrevistas semiestruturado, composto de dois eixos fundamentais: (1) A Definição de aqui-e-agora, que teve como objetivo reunir as conceituações teóricas do termo; (2) O Lugar que o aqui-e-agora ocupa na Prática Psicológica, que pretendeu investigar, por meio da solicitação de exemplos práticos, como esse tema é abordado na prática psicológica.

Todas as entrevistas foram gravadas e transcritas. A análise seguiu os seguintes passos metodológicos para a construção temática (Van Manen, 1990): 1. Abordagem holística, com leitura exaustiva das entrevistas; 2. Abordagem seletiva temática para apreensão do sentido; 3. Abordagem detalhada ou linha por linha e; 4. Agrupamento das expressões para a discriminação das Unidades Temáticas.

\section{Resultados e Discussão}

As análises das entrevistas resultaram em unidades temáticas que foram agrupadas em quatro grandes eixos, a saber: (1) O mal-entendido conceitual do aqui-e-agora; (2) Especialização do aqui-e-agora como contraposição a outras perspectivas temporais; (3) A definição do aqui-e-agora; e (4) O lugar do aqui-e-agora na clínica.

\section{0 mal-entendido conceitual}

Neste primeiro grupo uma suposta obviedade do significado do aqui-e-agora foi apontada por todos os entrevistados como origem de uma má compreensão frequente tanto acerca da fundamentação teórica do termo quanto de suas implicações para a prática clínica:

pra mim é um dos conceitos mais complicados da Gestalt porque é mal entendido geralmente" (E2); "você vai ter confusão porque quando vocêfala aqui-e-agora parece que você tá dizendo que não existe nem passado nem futuro, que só existe um presente (E1).

Para os participantes a desconsideração equívoca de outros tempos que não o presente, atua como se isto retirasse o sujeito da temporalidade: “dá a impressão de que realmente a gente não dá (...) importância nenhuma para história do passado do paciente (...) isso é tão errôneo quanto enfatizar o outro lado. Quer dizer, eu substituo a lógica, só isso" (E1). Ou seja, ao impedir a manifestação de um evento passado ou um projeto futuro, elimina-se parte da existência: "eliminar qualquer parte é eliminar a própria equação” (E1).

As hipóteses oferecidas pelos participantes para tentar explicar como esse mal entendido foi tão amplamente disseminado no contexto clínico podem ser verificadas nas seguintes unidades temáticas:

1. A divulgação da abordagem e de suas aplicações práticas:

a teoria da Gestalt-terapia, que não é uma teoria superficial no sentido da densidade, é muito densa. Mas foi apresentada já de uma maneira muito superficial, como sendo só exercício, só cadeira vazia, só isso, aquilo... mas não é (...) Então, eu vivi workshops em que você não podia falar do passado, tudo tinha que ser no presente, e não é assim. Então, houve um momento de radicalismo da própria Gestalt. O cliente dizia: 'eu me lembro...', [e o terapeuta] 'não, não quero saber de lembrança, quero saber do que está acontecendo agora em você' (E2). 


\section{O pragmatismo da abordagem:}

pensando agora talvez tenha sido isso [o experiencialismo] que tenha feito esse conceito ficar tão, tão, tão supostamente claro e ao mesmo tempo tão irremediavelmente sem desenvolvimento. Quer dizer, todo mundo acha óbvio (...). E o conceito de aqui-e-agora caiu nesse meio aí perdido... e você pinça lá como se fosse uma técnica (E1).

3. A falta de apropriação teórica por parte do clínico:

O clínico não se apropria do conceito, aí fica replicando, replicando, replicando (...). Então, tecnicamente você vai encontrar na literatura, e muita gente vai pensar dessa maneira, que o aqui-e-agora é esse, é como se fosse um grande momento de conexão emocionada entre terapeuta e cliente (...). Porque aí vai juntando o conceito pra tentar dar nome a uma coisa que é tacitamente inominável (E1).

\section{A falta de fundamentação da teoria:}

Acho que a imensa maioria não entendeu. Inclusive eu arriscaria dizer que boa parte dos grandes teóricos também esqueceram de vincular isso (...) Eu acho que as abordagens humanistas em geral, e falando especificamente da Gestalt, elas padecem de um erro muito grave de falta de fundamentação (E1).

Na apresentação à edição Brasileira do livro Gestalt-terapia Integrada, Bernardini (2001) já aponta que a obra surge da necessidade de desenvolver os conceitos teóricos da Gestalt-terapia que na época (1960-1970), devido a sua fase anti-intelectual, encontravam-se ainda muito desorganizados. Todos os participantes concordam - pelo menos no que se refere à noção do aqui-e-agora - que ainda hoje, mais de 40 anos depois, a frequente reprodução destas noções equivocadas impactam no exercício clínico: "Então mesmo para os Gestalt-terapeutas esse foi um conceito que teve que ser bastante digerido e ainda está sendo. Ainda tem gente negando a importância do passado, como se a gente não se construísse historicamente" (E2).

A análise das entrevistas mostrou, em concordância com Carmo (2004), que uma compreensão rígida do aqui-e-agora estaria desconsiderando o princípio gestáltico de totalidade e seu enfoque holístico, parcializando a vida:

então viva o imediato, viva o presente, não, não importa o futuro, quase como uma inconsequência. Isso não tem nada a ver com o conceito, esse conceito não é inconsequente, pelo contrário, ele é um conceito de extrema consequência, porque só agora é que eu posso fazer alguma coisa (...) e a Gestalt perdeu muito com isso, com essa má compreensão (E2).
Frente a esse cenário, em que há, pelos participantes, o destaque de uma prática que é desqualificada teoricamente e de uma teoria que não está produzindo o efeito desejado, é importante destacar a observação de Martins (2004) de que a energia da Gestalt-terapia se encontra no não aprisionamento da teoria e da prática. Isso é, a superação de um mal-entendido, tão amplamente propagado só pode se dar na integração dessas duas forças que constituem, afinal de contas, essa terapia de totalidades.

\section{Especialização do aqui-e-agora como contraposição a outras perspectivas temporais}

A constituição deste grupo temático organiza as informações que singularizam o significado do aqui-e-agora, fazendo deste um termo reconhecidamente utilizado na abordagem. Nesse sentido, é importante destacar que a contraposição pretendida com a noção de aqui-e-agora se refere à origem da Gestalt-terapia e de sua tentativa de superação dos paradigmas impostos pela psicologia da época, ou seja, à sua contraposição a outras perspectivas temporais em psicologia.

Este grupo reúne as seguintes unidades temáticas: 1. Reação a outros conceitos valorativos de temporalidade; 2. Maneira de restituir a autonomia do indivíduo e; 3. Reestruturação da postura do psicoterapeuta.

Na primeira unidade temática, a compreensão do aqui-e-agora incide como um posicionamento reativo, isso é, de reação a outras perspectivas valorativas de temporalidade: "Discutir aqui-agora na clínica só tem sentido em contraposição a outros conceitos de valoração (...) fazendo uma crítica a um modelo psicanalítico, a um modelo behaviorista, de época” (E1). No momento em que a Gestalt-terapia afasta-se das abordagens que encontram no passado um fundamento causal para explicar e tratar o sujeito é que o termo aqui-e-agora se especializa. Entretanto, apesar de valorizar o tempo presente na tentativa de romper com essa separação temporal para compreender a pessoa na sua totalidade, o aqui-e-agora se propagou com essa noção de ausência do passado e do futuro.

Na segunda unidade temática o aqui-e-agora aparece como tentativa de restituir a postura autônoma do paciente se opondo às lógicas causais e às relações de determinismo de outras abordagens:

é como se dissesse assim: 'você não é, você foi o que você é’, 'é o que você foi’ (...), é como se você não tivesse autonomia” (E1); "É impossível dizer que esta causa ou aquela foi determinante, não foi. E isso tem a ver, volto à questão, com a visão de homem. Nossa visão de homem é: o homem é ativo, interativo, responsável, autônomo e livre. Portanto, ele pode escolher. E as escolhas que ele faz são, do meu ponto de vista, por mais 
patológicas que sejam, os ajustamentos criativos possíveis, dadas aquelas circunstâncias e dadas aquelas possibilidades do indivíduo (E3).

O aqui-e-agora estaria permitindo, portanto, que o paciente seja autônomo para decidir quando e de que forma pretende estabelecer relações entre as vivências do presente, do passado e do futuro, ao invés de ficar à mercê das relações traçadas pelo terapeuta. Essa validação da autonomia do paciente implica necessariamente a mudança de postura do terapeuta (terceira unidade temática) que reconhece e considera os recursos disponíveis pelo paciente para lidar com suas questões:

É... terapias planejadas (...), por exemplo, elas fogem disso porque elas são guiadas por um planejamento. Então o que está planejado está no futuro, não está no aqui-e-agora. Por mais que esteja aqui, por mais que perceba o que está acontecendo, mas o olhar está lá no futuro, principalmente porque tem uma meta. As terapias mais fenomenológicas e aí eu acho que a Gestalt é a mais forte nisso... como a gente, embora tenha um projeto, embora tenha um horizonte para aquela terapia, a gente não tem uma meta e a gente pode ficar mais no que está acontecendo (...). Em outras psicanálises que eu percebo (...) ele foge um pouco do aqui-e-agora porque ele vai pro modelo anterior. Ele vai olhar o que que faltou na vida dessa pessoa que precisa ser reposto agora (...) Então ele [terapeuta] improvisa menos (...) Então eu [terapeuta] fico muito mais criativo, muito mais aberto à minha criatividade porque eu estou com o que tiver (E2).

Costa (2004) observa que as críticas proferidas às psicoterapias que trabalham a partir da noção do aqui-e-agora, estão sobre a influência unilateral e mecanicista do tempo. Dessa forma, a suposição de que a Gestalt-terapia exerce uma fixação no momento presente, desconsiderando outros tempos, só faz sentido numa análise linear do tempo, fruto de uma compreensão cristalizada na ciência cartesiana, objetiva e lógica. Considerando a base fenomenológica que estrutura a noção de tempo na Gestalt-terapia e, portanto, a noção de campo em que o presente está constantemente sendo reatualizado a partir de suas retenções e protensões, a concepção do termo aqui-e-agora se funda por meio de um outro paradigma temporal. E é nesse contexto que Perls et al. (1997) se contrapõem às psicoterapias que enfatizam a recuperação de um material censurado ou das antecipações para o futuro em detrimento da forma com que atua a censura, ou seja, como "o passado e toda outra fixidez persistem por meio de seu funcionamento presente” (p. 100).

É também por meio dessa contraposição que no contexto clínico a autonomia do paciente parece ser reestabelecida na relação terapêutica. O aqui-e-agora não estaria, então, apenas situando a Gestalt-terapia sob um paradoxo temporal diferente do de outras psicoterapias, mas apresentando uma nova concepção de homem. Perls et al. (1997) defendem que as terapias que se propõem a um processo retrospectivo tendem a culpabilizar as situações passadas inviabilizando que o paciente assuma a responsabilidade por sua vida e por suas ações atuais. A busca psicoterapêutica pelas reminiscências passadas enquanto causa e determinação da situação presente impediria, portanto, a compreensão da liberdade existencial humana. Frente a essa dinâmica, nota-se a possibilidade de uma postura psicoterapêutica responsável, aberta e criativa que reintegra ao paciente seu direito de escolha, considerando a disponibilidade dos recursos existentes. O desenvolvimento da experiência psicoterapêutica concreta acontece sem a utilização de artifícios, "pistas para um inconsciente desconhecido ou um sintoma” (Perls et al., 1997, p. 51) e reflete diretamente um protesto contra o autoritarismo do terapeuta e a psicologização com julgamentos de normalidade e anormalidade, isso é, a orientação de quem "supostamente sabe mais se impor sobre para quem sabe supostamente menos" (Costa, 2004, p. 37). Carmo (20014) ainda destaca a importância da postura assumida pelo Gestalt-terapeuta, que imerso nessa sociedade objetivista e causal que busca respostas práticas e rápidas, é quem sustenta a experiência respeitosa da relação terapêutica sem, contudo, prescrever sua própria concepção de mundo.

\section{A definição de aqui-e-agora}

As definições de aqui-e-agora apresentadas nas entrevistas versam sobre a temática do Fluxo de Temporalidade. Dessa forma, o aqui-e-agora é entendido como articulação de uma unidade temporal em que passado, presente e futuro se revelam continuamente a cada momento e não podem ser compreendidos separadamente: "Passado e futuro se constelam no aqui-e-agora. Eles se configuram no aqui-e-agora. Eles existem no aqui-e-agora" (E3).

O aqui-e-agora é compreendido como interação unificada da totalidade de forças passadas, presentes e futuras mutuamente influenciáveis. Ou seja, a perspectiva de linearidade e causalidade temporal é substituída por uma concepção fluida de campo, em que os todos os tempos estão constantemente sendo atualizados: "Aqui-agora é fluxo de temporalidade (...) no fluxo da temporalidade eu escolho abordar o momento presente, o instante, o imediato, a experiência, a vivência” (E1).

Ao escolher trabalhar em psicoterapia a experiência imediata, invariavelmente escolhem-se também os momentos passado e futuro que se articulam nesse fluxo temporal e que organizam o fundo sobre o qual o sujeito se constitui. Mesmo que o trabalho psicoterapêutico se debruce em uma memória passada ou em uma condição de possibilidade futura, a expressão da pessoa é figura 
de um campo de totalidade na relação não apenas com o mundo, mas com um mundo atravessado pela temporalidade: "o passado existe quando se lembra de alguma coisa” (E3). Por isso os eventos passados e futuros referidos são processos fluidos que não se manifestam de forma definitiva, mas são figuras emergentes no campo aqui-e-agora, que por sua fluidez, podem vir a ser outra figura logo a seguir:

o aqui-e-agora, de fato, é a única coisa que você pode ter acesso. Se você me contar a história da sua vida que aconteceu até hoje, você vai falar isso no agora, não tem outro jeito (...) aquilo que o paciente se lembra, se recorda, traz como história, como passado, não é necessariamente o que aconteceu. É aquilo que ficou registrado (...) e o que nós estamos interessados é como isto é vivido e que sentido tem para o paciente naquele momento (E3).

Dessa forma, passado, presente e futuro são entendidos a partir de suas instabilidades e mutabilidades, e especialmente, a partir de suas tensões e articulações, seja como fundo que constitui o sujeito, seja como elemento formador de novas figuras, os eventos estão continuamente se transformando e só podem ser desvelados no aqui-e-agora.

Identifica-se que nesse grupo há uma recuperação ontológica do sentido de temporalidade que rompe com as concepções lineares e determinantes do sujeito. O aqui-e-agora está concebido, no discurso dos entrevistados, pela permanência de todos os tempos vividos e, por isso, passado e futuro encontram lugar na estrutura da realidade presente. Isso, entretanto, não significa apenas a análise da memória e da antecipação como atos no presente, ou seja, a presentificação de todos os tempos, mas também, como observa F. Perls (2012) é a noção de que o presente é uma experiência em transformação constante. O aqui-e-agora se refere a uma configuração atual e em constante mudança que contém material novo do ambiente e não apenas a reunião de situações passadas, "é, portanto, diferente do que poderia ser relembrado (ou conjecturado)” (Perls et al., 1997, p. 48).

Costa (2004) descreve que a organização das memórias de pessoas que compartilharam uma mesma experiência, se dá de maneiras distintas. As relações que dão sentido e significado à experiência são retidas de diferentes formas e, portanto, são particulares, de modo que o sujeito não tem a posse do tempo passado, mas a retenção de como esse passado aparece agora para ele. Isto se apresenta em consonância com a perspectiva temporal husserliana, em que passado e futuro não estão no presente, mas se revelam por meio dele. Nesse sentido, Perls et al. (1997) acrescentam que qualquer passado que não seja de interesse do sujeito, ou seja, não está aparecendo através do presente, não é psicologicamente real.
Essa perspectiva de temporalidade que vem sustentar a compreensão do aqui-e-agora se encaixa nos próprios princípios gestálticos de totalidade, e sendo compreendida como fluxo, ela abarca o todo temporal ao invés de dividir partes da vida da pessoa em instantes estanques de passado, presente e futuro. Além disso, essa compreensão se faz inevitável, já que é o entendimento do aqui-e-agora enquanto fluxo temporal que oferece fundamentação ao estabelecimento do trabalho clínico e norteia o próprio fazer gestáltico.

\section{O lugar do aqui-e-agora na clínica}

Este último grupo reúne as descrições dos participantes sobre o lugar que o aqui-e-agora ocupa em sua prática clínica e apresenta os desdobramentos práticos das definições e fundamentações teóricas apresentadas nos eixos anteriores. Foi dividido nas seguintes unidades temáticas: 1. Conexão com a totalidade temporal da experiência; 2. Responsabilização; 3. Ressignificação; 4. Postura do terapeuta e; 5 . Problemática da utilização do aqui-e-agora enquanto técnica.

Na primeira, o aqui-e-agora é compreendido como unidade temporal que articula passado, presente e futuro. Há uma compreensão de que a possibilidade de conexão com a totalidade da experiência se vivencia no aqui-eagora e permite concentração ao imperativo da situação clínica, ao "que acontece naquele momento (...) ao que está acontecendo entre as duas pessoas” (E2).

Se o aqui-e-agora é definido por meio do fluxo de temporalidade, o termo, aplicado ao trabalho psicoterapêutico, pode se constituir como uma compreensão que produz uma certa inteligibilidade sobre as relações do cliente com a totalidade da sua experiência "Você fez isso daqui (fechar a mão) quando estava falando determinada coisa, que que isso quer dizer?. É uma maneira do sujeito se conectar como toda essa experiência” (E2). Ou como podemos testemunhar no exemplo de E3 que descreve um momento de seu atendimento clínico:

Então, neste aqui-e-agora, neste momento que ela [paciente] disse: 'fiz minhas unhas pela primeira vez', ela estava atualizando todo um passado, ela está trazendo todo um (...) 'eu consegui assumir minha 'mulheridade'. (...) Você percebe que neste momento (que ela mostra as unhas), isto é um momento, é num aqui e num agora que ela me mostra o esmalte das unhas. Que em si mesmo, objetivamente falando, não precisa ter um significado é só um esmalte qualquer: Risqué, Impala... Mas esse momento fala de toda uma história de vida passada e futura. Eu quase ousaria dizer que é um 'turning', né, um ponto de virada. Foi um momento decisivo para o processo dessa mulher, de parar de sofrer. Ela sempre se considerou vítima de um pai que a abusou, e ela foi vítima desse pai; mas 
ela não é mais. Não a impede de pintar as unhas e ser mulher atraente.

O aqui-e-agora aparece, então, como possibilidade de conexão do sujeito à totalidade da sua experiência temporal como demonstra E1 ao defender a consideração também dos eventos passados: "isso não significa anular o meu passado, porque na verdade é a inversão, significa assim: Aproprie-se do teu passado como teu".

A segunda unidade temática pretende mostrar que a noção do aqui-e-agora alicerça uma psicoterapia em que há o estímulo à apropriação e responsabilização do paciente pela sua própria vida e pelos eventos que está narrando. A maneira com que isso ocorre na prática clínica, entretanto, aparece de formas diversas para os dois entrevistados que discorreram sobre o tema. Para E1 o aqui-e-agora seria a forma de integrar a pessoa à sua própria experiência, retirando-a de um mero "falar sobre":

observar quanto que o paciente conseguia vivenciar uma parte da fala dele. Isso eu sempre fico atento. O que ele fala, vamos dizer, é uma fala presente ou uma fala etérea? (...) é como se (o paciente) estivesse falando em terceira pessoa. Então o aqui-e-agora seria uma espécie de convite para ele se apropriar disso 'oh essa vida que você tá falando aqui é tua'!

Enquanto para E3, nenhuma fala do paciente seria etérea e, portanto, independente do conteúdo, esta também levaria a integração do sujeito à sua experiência. Ou seja, inclusive a narrativa aparentemente desconexa está implicada na conexão com a totalidade temporal do paciente:

A minha experiência é: não importa o que o cliente esteja falando, ele está falando de coisas que estão acontecendo agora. Sempre. E ele está falando de coisas importantes de serem ditas. Ainda que essa forma de dizer possa ser algo como: 'Nossa, ontem choveu, né'; ou 'Ah! Eu vou viajar esse fim de semana, queria tanto que não chovesse!'. Parece que é uma fala que não tem nada haver. E a princípio não tem. (...) Conforme o paciente fala mais coisas você vai percebendo que tem uma ligação. As coisas estão ligadas (...). Nada do que dizemos, fazemos ou pensamos é à toa.

Seria, então, por meio da apropriação e responsabilização da pessoa pelos eventos da sua própria vida que a ressignificação (terceira unidade temática) pode se dar, isto é, conectar o fluxo temporal permite a mudança terapêutica de ressignificação:

Eu não sou vítima de um passado, eu posso mudar isso e eu posso até transformar isso, né (...) questão da possibilidade de transformação a partir de você se dar conta dos recursos que você tem. Não que você mude o que aconteceu, você muda a compreensão que você tem daquilo. E na medida que você muda a compreensão você pode usar, passar a usar aquilo como um recurso" (...) E nesse sentido, o passado de novo se faz presente. Só que aí de uma outra forma, não como lembrança mas como transformação. E aí transforma inclusive o passado. Então, nenhum passado é estático (E3).

A implicação para que a autonomia do paciente seja restituída na relação psicoterapêutica é que haja uma mudança da postura do próprio terapeuta (quarta unidade temática) de modo que os acontecimentos são compreendidos a partir dessa relação, como fica demonstrado no exemplo de E3 sobre um atendimento assistido no qual estava participando:

a problemática que o paciente traz é a dificuldade com mulheres, e eu: 'e é mesmo, mas porque, como...'. Aí o [instrutor] me interrompe e diz assim: 'Você é uma mulher'! (...) 'Fala comigo, como é comigo?'. Está aqui, a gente não precisa ir lá. Mas não é fácil perceber isso, não é fácil.

O aqui-e-agora também aparece, nesta unidade, como um momento em que a presença, a possibilidade genuína de aceitação e disponibilidade, excede a comparência e permite alcançar o ponto de virada, de conscientização, ou de percepção que a pessoa possa ter de si mesmo e que promove transformação. É, portanto, para além de qualquer técnica, um momento que permite a emergência da situação clínica: "Aqui-e-agora não é o mesmo que presente (...) aqui-agora é como se fosse uma ênfase, uma escolha, um ponto de partida; como se fosse um porto-seguro, uma âncora pra qual eu possa basear uma ação interventiva" (E1).

A quinta unidade temática (a problemática da utilização do aqui-e-agora enquanto técnica) surge como forma de reiterar o aqui-e-agora enquanto fluxo de temporalidade. Isso porque o termo não aparece, na prática clínica descrita pelos entrevistados, relacionado a uma técnica específica. Ou seja, os exemplos práticos estão de acordo com a concepção processual de sujeito e não de um caminho facilitado pela técnica, que saciaria o julgamento do terapeuta mais do que possibilitaria ao paciente usar seus recursos quando disponíveis.

Nesse sentido, dois entrevistados não mencionaram o termo associado a nenhuma técnica e um deles ainda destacou que apesar da dificuldade em fugir da utilização de artifícios, recursos e estratégias para "promover" o aqui-e-agora, é necessário refletir sobre a problemática que isso pode acarretar:

Então ele acaba sendo confundido com uma técnica e não é 'Ah eu uso o aqui agora' 'Tá, você usa o aqui agora, que legal... você usa o aqui agora, ainda bem porque se não, né?' Porque se eu usasse o passado eu jamais teria uma terapia, né, eu sempre marcaria e 
desmarcaria porque já foi, né (...) até entendo que é razoável pensar tecnicamente. Só que de novo pensar tecnicamente assim é reduzir o aqui-e-agora a um construto, uma operatividade, criando inclusive um problema terrível do tipo: 'eu vou criar formas para que isso aconteça, eu vou criar técnicas para que...'. Então tá, vamos criar técnicas para o apaixonamento (...) é uma mitologia que se cria. E aí paradoxalmente se perde o fluxo, né (E1).

Neste grupo foi possível perceber que os exemplos práticos que abrangem o tema são congruentes com as definições teóricas do eixo anterior. Nessa perspectiva, o aqui-e-agora não é considerado por meio de uma operatividade, isto é, enquanto técnica, mas como o que fundamenta a visão de homem livre e autônomo, a prática clínica direcionada à responsabilização do paciente por sua própria vida e o trabalho com os recursos disponíveis no momento. Portanto, falar na conexão com a totalidade de experiência proporcionada pelo aqui-e-agora não significa objetivar o termo, mas inseri-lo como constituinte da visão de homem não determinado temporalmente com a qual o terapeuta embasará seu trabalho.

Esta concepção de experiência dada no fluxo de temporalidade parece restituir a autonomia e a responsabilidade do paciente, além de possibilitá-lo a ressignificação. Considerando que desde seu surgimento essa dinâmica terapêutica pretendia se distanciar da psicologia que estava sendo articulada, a aplicação prática dessa abordagem implica na mudança de postura do terapeuta que renuncia uma posição de autoridade e não mais detém o poder da interpretação sobre as manifestações do paciente. Dessa forma, podemos afirmar que o aqui-e-agora não implica apenas na conexão à totalidade da experiência do paciente, mas também na concepção de experiência do terapeuta perante a relação clínica que se estabelece.

\section{Considerações finais}

Este trabalho partiu de uma constatação cotidiana de que haveria uma confusão envolvendo o termo aquie-agora, o que resultaria em práticas equivocadas em Gestalt-terapia. Por meio de entrevistas com os profissionais vinculados à produção teórica em Gestalt-terapia pretendeu-se em primeiro lugar verificar se essa observação sobre um mal-entendido era procedente. Além disso, em segundo lugar, buscou-se uma compreensão mais aprofundada sobre o tema que, como foi demonstrado na introdução, está pulverizado pela literatura. Dizendo de outro modo buscamos, como propôs Husserl, um retorno às coisas mesmas, a partir da produção de uma pesquisa da análise fenomenológica pautada na descrição e compreensão da experiência do termo, procurando analisá-lo apenas do ponto de vista teórico, mas também a partir de seu aparecimento na clínica praticada pelos entrevistados.
As entrevistas possibilitaram a configuração da perspectiva de um aqui-e-agora como fluxo temporal que excede seus relevos habituais frequentemente associados a uma técnica ou método terapêutico. O termo refere-se, portanto, à visão de homem e de mundo na qual se alicerça a abordagem, assim como à sua proposta de abertura de novas possibilidades psicoterapêuticas. $\mathrm{O}$ aqui-e-agora se organiza na estrutura da experiência temporal onde são possíveis, na integração criativa situacional, as relações dinâmicas entre figura e fundo, unidade e des-unidade, passado, presente e futuro (Perls, 1997).

Conforme defendido por Costa (2004) o trabalho gestáltico no aqui-e-agora estaria incluindo o ser em sua temporalidade existencial e dessa forma permitindo a ressignificação das suas experiências vividas. Por isso, quando nas entrevistas se posiciona o aqui-e-agora como "possibilidade de restituição da autonomia do paciente", "permitindo a ressignificação" ou "propondo a mudança de postura do terapeuta”, o termo se apresenta menos em um contexto de objetificação, como método que permite alcançar objetivos e, mais como uma perspectiva, um modo de pensar e atuar que subsidia a concepção total do fazer clínico. Isto é, o aqui-e-agora não pode ser compreendido enquanto instrumento que permite ou facilita a awareness, a concentração e o ajustamento criativo, mas como sendo uma noção que subsidia a perspectiva de self temporal, norteando a atuação do Gestalt-terapeuta e, portanto, um modo de pensar e estar com o cliente na psicoterapia. O aqui-e-agora surge, então, não apenas como uma mudança da perspectiva temporal, cognitiva, da prática clínica, nem apenas como o afastamento de processos interpretativos, mas como reposicionamento de um terapeuta, antes no lugar da autoridade e da detenção de saber, para um lugar de facilitador da organização e integração do fluxo de vivências da pessoa (Perls, et al., 1997; Carmo, 2004; Costa, 2004).

Apesar da narrativa dos entrevistados não refletir o mal-entendido que se supunha existir em relação ao termo, as entrevistas, assim como a revisão bibliográfica, apontam para a frequência dessa prática. Na tentativa de oposição às perspectivas que ao valorizar o passado incidiam no determinismo e na elaboração de explicações causais, a Gestalt-terapia lançou um movimento de valorização do tempo presente (Perls, 1942/2002; Perls et al., 1997). Essa apropriação da existência presente como possibilidade do processo de awareness parece ter aberto espaço para ocorrência de uma inversão lógica, que tendo como base uma perspectiva temporal linear, inseriu o aqui-e-agora como sinônimo de tempo presente. Com isso, enfatizou-se o trabalho psicoterapêutico no contexto da situação presente em detrimento das situações passadas e futuras da pessoa, ou seja, inserindo o tempo presente desconectado e qualitativamente mais importante do que os outros tempos.

Quando se analisa o aqui-e-agora é necessária a distinção e o afastamento das concepções lineares, objetivas 
e mecânicas que fundamentam as ciências exatas e naturais (Costa, 2004; Marques 2008). Nesse sentido, ou se compreende o termo a partir da noção de fluxo temporal para discutir o aqui-e-agora por meio de uma perspectiva fenomenológica, ou incorre-se no erro de encaixar a noção de aqui-e-agora na perspectiva temporal linear e transformá-lo em sinônimo de tempo presente.

A literatura frequentemente oferece uma analogia entre o aqui-e-agora e o termo "presentificar" (Costa, 2004; Polster \& Polster, 2001). O que propomos aqui é a diferenciação do aqui-e-agora inclusive da noção de presentificação. Ao que nos parece, presentificar remete mais à rigidez de encaixar um evento passado ou futuro estáticos no momento presente absoluto. Com o aqui-e-agora pretende-se a referência a um encontro renovado e inesperado do passado, presente e futuro na concretude da experiência atual. Isto é, se propõe uma reflexão de que o aqui-e-agora remonta mais à noção de que passado, presente e futuro são modulações de um único tempo, como descreve Santo Agostinho (1981), do que uma simples presentificação do passado e do futuro, como se houvesse um instante presente valorativamente mais importante do que os outros tempos. Na prática clínica, uma interrupção se dá no presente, entretanto, em um momento em que a pessoa se encontra impedida de criar, configurar e transitar desde o passado até o futuro. O aqui-e-agora não significa, portanto, apenas estar presente, mas estar fluindo no campo temporal da sua existência, a partir de uma abertura de possibilidades, de retenções e protensões desvelados no presente e em trânsito constante. Talvez a falta de referências atualizadas sobre o tema, a pouca clareza das obras clássicas, assim como o possível distanciamento dos profissionais e da própria Gestalt-terapia com a fundamentação fenomenológica da abordagem, dificulte a compreensão aprofundada do termo, assim como suas facetas e limitações. Disso decorrem problemas linguísticos, como, por exemplo, "meu aqui-e-agora”, que algumas vezes durante as entrevistas pareciam estar objetificando o termo.

As articulações linguísticas, tanto no que concerne as definições do termo aqui-e-agora quanto no modo de articulá-lo à prática clínica, foram reveladas neste trabalho como uma limitação que também parece se impor à própria teoria gestáltica. Entende-se que a superação de uma linguagem objetificante que reduz o termo a instrumentalidade de um construto é um desafio apenas passível de superação por meio de um retorno às raízes filosóficas que orientam a abordagem. Além dos desafios linguísticos explicitados, este trabalho encontrou limitações principalmente no que se refere à possibilidade de articulação das noções de aqui-e-agora e corporeidade. Apesar de referida na literatura, a corporeidade parece ter sido esquecida quando problematizados os desdobramentos práticos do aqui-e-agora.

A partir do termo aqui-e-agora, este trabalho pretendeu abrir uma discussão sobre a diversidade de possibilidades na apreensão de conceitos fundamentais em Gestalt-terapia. Espera-se que essa aproximação possa evidenciar as implicações distorcidas de um fazer clínico comprometido exclusivamente com o pragmatismo da abordagem, assim como contribuir para uma compreensão mais aprofundada sobre temas que envolvem a Gestalt-terapia. Dessa forma, destaca-se a necessidade da realização de outros estudos que possam refletir as aproximações entre Gestalt-terapia e Fenomenologia que não pode ser aprofundada no escopo do presente trabalho, assim como as relações entre Aqui-e-agora e Temporalidade, especialmente no que se refere às implicações de se pensar a corporeidade como lugar da experiência e consequentemente da articulação temporal (incorporação) do sujeito.

\section{Referências}

Bernardini, R. G. (2001). Apresentação à edição brasileira. Em E. Polster, Gestalt-terapia integrada (p. 9-12). São Paulo: Summus.

Carmo, M. (2004). O Aqui-e-agora e a emergência da subjetividade no processo psicoterápico. Revista do X Encontro Goiano da Abordagem Gestáltica: O aqui e o Agora Gestáltico, 10, 29-32.

Costa, V. E. S. M. (2004). O Aqui-e-agora em uma perspectiva clínica. Revista do X Encontro Goiano da Abordagem Gestáltica: O aqui e o Agora Gestáltico, 10, 33-41.

D’Acri, G., Lima, P. \& Orgler, S. (Orgs). (2012). Dicionário de Gestalt-terapia [versão Google Ebook]. Recuperado em http://books.google.com.br/books?id=gJ1caLrn2ioC\&pg=PA4 \&lpg $=$ PA4\&dq=Dicion\%C3\%A1rio + Gestalt\%C3\%AAs\&so urce $=$ bl\&ots $=$ nhCiHKY3ga\&sig $=$ LUC5smTD8YHxdVBnTo NJqnon24I\&hl $=$ en\&sa $=$ X\&ei $=$ jk1DVOLIONC6ggSntIKAD g\&ved $=0 \mathrm{CD} 8 \mathrm{Q} 6 \mathrm{AEwBA} \# \mathrm{v}=$ onepage \&q=Dicion\%C3\%A1 rio\%20Gestalt $\%$ C3\%AAs\&f $=$ false.

Martins, A. E. O. (2004). Em nome da Gestalt-Terapia. Revista do X Encontro Goiano da Abordagem Gestáltica: $O$ aqui e o Agora Gestáltico, 10, 21-24.

Marques, J. B. (2008). O conceito de temporalidade e sua aplicação na historiografia antiga. Revista de História, 158, 43-65.

Mesquita, G. R. (2011). O Aqui-e-agora na Gestalt-Terapia: um Diálogo com a Sociologia da Contemporaneidade. Revista da Abordagem Gestáltica, 17(1), 59-67. Recuperado em http://pepsic.bvsalud.org/scielo.php?script=sci_arttext\&pid $=$ S1809-68672011000100009.

Perls, F. (2002). Ego, Fome e Agressão (G. Boris, trad.). São Paulo: Summus. (Original publicado em 1942)

Perls, F. (2012). A abordagem gestáltica e testemunha ocular da terapia (J. Sans, trad.). Rio de Janeiro: LTC.

Perls, F., Hefferline, R. \& Goodman, P. (1997). Gestalt-terapia (F. R. Ribeiro, trad). São Paulo: Summus.

Polster, E. \& Polster, M. (2001). Gestalt-terapia Integrada (S. Augusto, trad.). São Paulo: Summus. 
Saddi, S. A. L. M. (2004). O que se faz em nome da Gestalt-terapia? Sobre a interpretação. Revista do X Encontro Goiano da Abordagem Gestáltica: O aqui e o Agora Gestáltico, 10, 25-27.

Santo Agostinho (1981). Confissões (J. O. Santos \& A. A. Pina, trads.). São Paulo: Nova Cultural.

Van Manen, M. (1990). Hermeneutic Phenomenological Reflection. Em M. V. Manen, Researching lived experience: human science for an action sensitive pedagogy (p. 77-109). Ontario: The University of Western Ontario.

Paula Rocha - Psicóloga, Graduada pela Universidade Federal do Paraná. Email: arenhartpaula@gmail.com

Joanneliese de Lucas Freitas - Doutora em Psicologia, Professora Adjunto de Psicologia na Universidade Federal do Paraná, Curitiba. Endereço Institucional: Depsi/UFPR, Praça Santos Andrade, $n^{\circ}$ 50, Sala 215 (Ala Alfredo Buffren), CEP: 80.020-300, Curitiba - PR.Email: joanne@ufpr.br

Recebido em 22.06.15

Aceito em 02.03.16 